\title{
Anabases
}

ANABASES Traditions et réceptions de l'Antiquité

9 | 2009

Varia

\section{Rita FELSKI (éd.), Rethinking Tragedy}

\section{Geneviève Hoffmann}

\section{OpenEdition \\ Journals}

Édition électronique

URL : http://journals.openedition.org/anabases/567

DOI : 10.4000/anabases.567

ISSN : 2256-9421

\section{Éditeur}

E.R.A.S.M.E.

\section{Édition imprimée}

Date de publication : 1 mars 2009

Pagination : 324-326

ISSN : 1774-4296

\section{Référence électronique}

Geneviève Hoffmann, «Rita felskı (éd.), Rethinking Tragedy », Anabases [En ligne], 9 | 2009, mis en ligne le 01 juillet 2011, consulté le 21 septembre 2020. URL : http://journals.openedition.org/anabases/567 ; DOI : https://doi.org/10.4000/anabases.567

Ce document a été généré automatiquement le 21 septembre 2020.

(c) Anabases 


\title{
Rita FELSKI (éd.), Rethinking Tragedy
}

\author{
Geneviève Hoffmann
}

\section{RÉFÉRENCE}

Rita FELSKI (éd.), Rethinking Tragedy, Baltimore, The John Hopkins University Press, 2008, $368 \mathrm{p}$. 24,95 dollars (PB), 65 dollars (HC)/ ISBN 13 978-0-8018-8740-6.

1 Quatre ans après New Literary History, publié en 2004 par l'Université de Virginie, ce nouveau volume, dirigé par Rita Felski, réunit seize contributions dont certaines ont été publiées dans le précédent ouvrage. Son propos est de reconsidérer la tragédie à la lumière des travaux les plus récents dans une perspective pluridisciplinaire qui prend en compte la tragédie non seulement comme genre littéraire, mais l'esprit du tragique sur la longue durée, de l'acception romantique à l'usage vernaculaire.

2 L'ouvrage de 368 pages se compose de quatre parties. Les deux premières ont pour objet de définir la tragédie comme genre («Defining tragedy », 94 pages) et de repenser son contexte (« Rethinking the history of tragedy », 68 pages). Les deux autres volets du livre traitent des rapports entre tragédie et modernité d'une part (85 pages), et entre tragédie, cinéma et culture populaire d'autre part (59 pages). Le recueil comprend en outre une présentation des auteurs (p.347-350) et un index (p.351-368). Dans une introduction lumineuse, Rita Felski présente chacune des contributions et jette les bases de l'ouvrage, dont le propos premier est de discuter la thèse développée par George Steiner dans Mort de la tragédie (1961) en l'opposant à l'analyse de Terry Eagleton, qui clôt le recueil par un véritable réquisitoire contre « the right-wing deathof-tragedy thesis ».

3 George Steiner ouvre le recueil en rappelant que si le concept de tragédie s'étend bien au-delà du genre lui-même - de l'épopée d'Homère à la musique de Brahms - le genre, tel qu'a pu le définir Aristote, n'a pu s'épanouir selon lui que pendant deux périodes : l'Athènes $d u v^{e}$ siècle avant J.-C. et l'Europe des XVI et XVII ${ }^{e}$ siècles. La flamme de la tragédie s'est éteinte à cause du christianisme, du marxisme et de l'optimisme militant 
des démocraties occidentales (p. 29-44). Simon Goldhill s'interroge pour sa part sur la dimension politique du genre (p. 45-65) en soulignant que le définir a relevé d'un jeu (" a competitive game »), dont ont été friands Schelling, Hegel, Nietzsche, Kierkegaard entre autres. Wai Chee Dimock nous invite à élargir la conception du tragique aux catastrophes naturelles qui mettent en danger la survie de l'espèce et dont il trouve des exemples dans la littérature grecque, d'Homère à Euripide, pour décrire la ruine de Troie («After Troy. Homer, Euripides, total war », p. 66-81). Kathleen M. Sands se place au cœur du débat qui oppose T. Eagleton à G. Steiner, en rappelant que pour les féministes, la tragédie n'a pas perdu de son efficacité puisqu'elles y voient une forme d'aliénation patriarcale. Pour ce faire, elle se fonde sur l'analyse du mythe d'Ædipe par Carol Gilligan dans son livre The Birth of Pleasure (New York, 2002), qui traduirait une négation radicale du désir féminin. Joshua Foa Dienstag ( Tragedy, pessimism, Nietzsche », p. 104-123) se situe lui aussi au cœur de ce même débat en l'approchant par la thèse du pessimisme comme notion philosophique. Il revient au sens que Nietzsche lui avait donné dans le sous-titre de son livre : Naissance de la tragédie (1886), dans lequel il associait « hellénisme et pessimisme ».

Dans la seconde partie, le contexte historique de la tragédie est réévalué par l'étude de certains thèmes. Ainsi Page Dubois ("Toppling the hero : polyphony in the tragic city ", p. 127-147) dresse-t-elle l'inventaire des interprétations erronées qui depuis Aristote négligent le moment de la naissance du genre, dont Jean-Pierre Vernant et Pierre Vidal-Naquet - elle le rappelle à propos - ont relevé la spécificité historique. Elle souligne qu'à côté du héros tragique se fait entendre une polyphonie dont la voix des esclaves n'est pas absente. En se fondant sur le Philoctète de Sophocle, Martha C. Nussbaum explore la pitié (p. 148-169) comme notion tragique et philosophique. Simon Critchley, quant à lui, situe la Phèdre de Racine dans le contexte du jansénisme et explique le mal de vivre de l'héroïne par son malaise existentiel, né du refus du monde présent et de son aspiration à un absolu absent.

5 Dans la troisième partie: "Tragedy and modernity» (p.199-284), David Scott s'interroge sur la dimension tragique de notre présent ("Tragedy's time», p. 199-217) en se fondant sur les études de Paul Ricœur et en prenant pour cible l'ouvrage de C.L.R. James: The Black Jacobins, publié en 1938. Exercice historique, ce livre, contrairement aux Damnés de la Terre de Franz Fanon, n'était pas un brûlot anticolonial, dans sa première mouture. Republié en 1963, l'ouvrage inclut une dimension tragique grâce au héros Toussaint Louverture, pour interroger le lecteur sur la capacité des Noirs à déterminer leur destin politique. L'étude de Stanley Corngold (p. 218-240) nous conduit vers un monde tout à fait différent: celui de l'univers du poète allemand W.G. Sebald (1944-2001), dont le style tragique est à même d'exprimer la mélancolie d'une conscience confrontée aux images de l'horreur nées d'un passé récent. La littérature allemande est également à l'honneur avec la contribution d'olga Taxidou sur la mise en scène par Brecht de l'Antigone d'Hölderlin en 1948 (p. 241-262), photographiée par Ruth Berlau. Timothy J. Reiss se tourne vers la littérature de l'Afrique de l'Ouest pour souligner que les auteurs africains, à partir des années 1960, ont su adapter à leur culture et à leurs modes d'expression les mythes grecs, pour exprimer les tensions du monde postcolonial.

6 La quatrième partie sur les rapports entre tragédie, cinéma et culture populaire, comprend deux analyses de film. La première proposée par Elisabeth Bronfen interroge le personnage de la «femme fatale» dans le film de Billy Wilder, Double Indemnity 
(Assurance sur la mort, 1944). Loin d'être le produit des anxiétés masculines, la femme fatale peut être comprise comme un caractère tragique, dans la mesure où l'héroïne assume la responsabilité de ses actes et de leurs conséquences. C'est Mulholland Drive (2001) que Heather K. Love a choisi pour cerner la représentation ambiguë que David Lynch donne des lesbiennes, en explorant la dimension tragi-comique de certaines situations tout en se jouant avec brio des clichés d'une idéologie machiste (p. 302-318). Michel Maffesoli, professeur de sociologie à Paris V et seul auteur dont les livres ne sont pas en langue anglaise, élargit la problématique par sa contribution, « The return of the tragic in postmodern societies » (p. 319-336), en relevant les symptômes culturels d'une société occidentale caractérisée par le repli identitaire, l'esprit tribal, le développement des sectes et du surnaturel. Comme dans la Grèce antique, « la culture du plaisir marche main dans la main avec la conscience tragique du destin ». L'ultime contribution: "Commentary» (p. 337-346) de Terry Eagleton, tient lieu à la fois de passage en revue des arguments développés dans tout le volume et de conclusion. Auteur de Sweet Violence: the Idea of the Tragique, Oxford, 2003, il s'oppose avec virulence à la position défendue par George Steiner. Dans le contexte d'un monde encore dominé par l'Amérique de Bush, il défend l'idée que la modernité, loin d'éloigner le tragique, donne les conditions nécessaires à son épanouissement, par l'exploitation et l'aliénation dont elle se rend responsable. La violence est aux portes du monde civilisé, qui en conçoit plus de terreur que de pitié.

7 Ce recueil témoigne d'un débat vivant, parfois rude, mais toujours en prise avec des questions qui donnent sens au monde actuel. À ce titre, il mérite tout notre intérêt même s'il privilégie la thèse hostile à celle de George Steiner. Cet ouvrage le prouve : le tragique surgit en d'autres lieux que la scène, parfois sous d'autres écritures que celles du théâtre. Il suffirait de l'identifier sous ses différents masques pour retrouver Dionysos, plus vigoureux que jamais.

\section{AUTEURS}

\section{GENEVIÈVE HOFFMANN}

Université de Picardie-Jules Verne genevieve.hoffmann@wanadoo.fr 